\title{
CURRÍCULO: POSSIBILIDADES ATUAIS PARA EDUCAÇÃO
}

Ana Cláudia da Silva Rodrigues PPGE/DFE/CE/UFPB

As políticas curriculares, nas últimas duas décadas, têm protagonizado o debate sobre os rumos da educação do Brasil. A partir de 1996, com a promulgação da LDB 9394/96, as normativas relacionadas a educação foram elaboradas e implementadas apresentando um caráter neoliberal, ajustadas as perspectivas políticas, culturais e sociais que o governo do então presidente Fernando Henrique Cardoso representava. Porém, com a ascensão do presidente Luís Inácio Lula da Silva, em 2002, ao governo federal, e até a primeira gestão da presidente Dilma Rousseff, se passaram 20 anos de tentativas de efetivação de atendimento de demandas sociais vinculadas aos considerados grupos minoritários e as discussões pós-críticas se fizeram presentes nos discursos curriculares.

O campo dos estudos sobre o currículo no Brasil, neste período, se constitui como um dos espaços mais estimulante entre pesquisadores e docentes que vivenciam os processos de transformações da sociedade que interferem nas formações dos sujeitos sociais. Novas perspectivas curriculares emergiram do contexto escolar e estudiosos se debruçaram sobre o tema buscando compreender a escola, e o processo de formação das identidades dos sujeitos que a compõem e como as políticas curriculares interferem nesta constituição.

Lopes, Cunha e Costa (2013, p. 395) ao se referir ao termo "política" afirmam que este "expressa um deslocamento das formas sedimentadas do social constituintes da política institucionalizada, sendo marcado pela compreensão do social como sem fundamentos", tal conceituação para os autores transcende aos domínios da política. Para Ball (1992) as políticas devem ser compreendidas a partir de elementos instáveis e contraditórios em constante movimento através de tempo e espaço, apresentando incertezas de onde chegará.

Ainda tratando da Política, Lopes (2013, p.20) sugere uma ampliação desse significante, passando o que está instituído a priore uma dimensão da política chamada, o político, espaço em que são "desenvolvidas em todas as ações cotidianas, referentes às dimensões ontológicas de constituição do social", Destarte, a política é conflito e movimento permanente, marcada pelas disputas para significação e atribuição de sentidos, em todo os espaços sociais constituídas pela ausência de regras que caracterizem a política correta previamente estruturada. . Por isso, não se compreende políticas educacionais distantes das pessoas, já que a tomada de decisão nos constitui como sujeitos, sendo as decisões sempre contingentes o que exige uma indeterminação, como, bem coloca a autora "toda a opção política é sempre uma opção num conjunto imprevisto de possibilidades" (2013, p. 20) . Por serem resultados de processos históricos de constituição de sujeitos, as políticas se configuram como responsáveis por sua criação em momentos históricos distintos, que serão posteriormente "recriadas" em outros espaços, por outros sujeitos, em outras realidades, dependendo de quem detém a hegemonia, pois detém o poder de decisão.

O momento conjuntural passado nas últimas décadas constatou que "os livres mercados triunfaram e as reformas educacionais ecoaram os reforços para estratificar e diferenciar os mercados globalizados" (GOODSON, 2008, p.25), o que tornou as escolas "motores para a eficiência e para a diferenciação" sem observar a busca por igualdade e justiça social. Observa-se que no Brasil, as organizaç̃̃es internacionais têm contribuído para a homogeneização dos modelos educacionais. Estes modelos têm inspirado novas prioridades, principalmente a tendência à descentralização e à privatização. 
Apple afirma que o "currículo nunca é apenas um conjunto neutro de conhecimentos, que de algum modo aparece nos textos e nas salas de aula de uma nação. Ele é sempre parte de uma tradição seletiva" (APPLE, 2000, p. 59). Currículo é poder. Por isso, a necessidade de se voltar para a política curricular nacional.

Rosa (2013) destaca que para Ball (2012) se faz necessário pesquisar a "encenação das políticas" por ele denominada de policy enactments visto que implica em realizar trabalhos de envolvimento e das subjetividades nos processos "de leitura, interpretação e tradução das políticas em práticas concretas e institucionalmente situadas” (p.458).

Neste sentido, este dossiê centra seu campo problemático nesse período histórico, onde os estudos voltados as políticas curriculares se caracterizam e se articulam a partir de conceitos como enunciação, hibridismo, cotidiano e multiplicidade de acontecimentos (PINAR, 2007). A questão principal consistiu em compreender como os movimentos em defesa de setores específicos da educação ampliam o debate com um governo federal, instituído e consolidado como de disputa, em defesa de uma política para a Educação do Campo; Educação Infantil; Educação de Jovens e Adultos; Educação Inclusiva e Educação Integral? De que forma estas ações possibilitaram novas políticas curriculares? Quais avanços e retrocessos observam-se nos currículos escolares para estes setores específicos? A materialização do currículo, através da prática pedagógica, conduz as novas vertentes e experiências que ampliam estes corpus teóricos e possibilitam o surgimento de novos itinerários educativos?

É nesta perspectiva, de compreender como as políticas de currículo se constituíram durante este período de mudanças políticas e ideológicas, que este dossiê se insere. Para contribuir com a reflexão, autores de reconhecimento nacional e internacional compartilham suas pesquisas e partilham suas considerações. Com o intuito de organizar e facilitar a leitura dos artigos, organizamos esta proposta de dossiê em duas partes destinadas a interlocução de palavras e pensamentos, mediados pelos teóricos que representam as respectivas áreas.

Na primeira parte, apresentam-se os artigos organizados a partir das modalidades de ensino da educação no Brasil. Inicia-se com os textos de autores que estudam e pesquisam a Educação do Campo no Brasil e na Espanha. O primeiro intitulado El binomio educativo de los colegios rurales agrupados y los centros rurales de innovación educativa: un referente de calidad organizativa y pedagógica para la escuela rural de teruel (España) da professora Pilar Abós Olivares, Facultad de Ciencias Sociales y Humanas, Universidad de Zaragoza e Lorenzo Lacruz, Facultad de Educación, Universidad de Zaragoza, expõem a história dos Centros Rurais de Inovação Educativa de Teruel(Espanha), criado em 1983/1984 com o intuito de busca pela qualidade e equidade da educação rural.

O segundo texto, intitulado de Formação continuada de professores através de oficinas pedagógicas: uma contribuição ao currículo das escolas do campo, foi proposto pelo professores Luciélio Marinho da Costa DFE/CE/UFPB e de Maria do Socorro Xavier Batista DHP/CE/UFPB, docentes vinculados ao PPGE/UFPB, aborda a formação de professores, através de um projeto de pesquisa e extensão realizado em um assentamento rural da cidade de Sapé-PB.

No terceiro texto, intitulado Curriculum y escuela rural en Cataluña de autoria da professora Roser Boix Tomás, Facultad de Educación, Universitat de Barcelona, destaca-se a constituição de um currículo escolar com ênfase no território rural e nas salas multisseriadas, que ajudará na compreensão e reflexão sobre estes espaços de aprendizagem do Brasil.

O artigo A construção do currículo no Programa Escola Zé Peão, do professor Eduardo Jorge Lopes da Silva, vinculado ao Programa de Pós-graduação em Educação da Universidade Federal da Paraíba, compreende o currículo como uma construção cotidiana, que leva em consideração o acúmulo da experiência do fazer pedagógico e os interesses de aprendizagem dos operários-educandos, demonstrando possibilidades de (re)construções e itinerários próprios para esta modalidade de ensino.

No quarto texto, Os currículos pensados para a educação da infância no Brasil e em Portugal: alguns apontamentos! de autoria de Ana Paula Braz Maletta e Magali dos Reis, professoras do Núcleo de Pesquisa Social: Teoria Crítica da Sociedade, Cultura e Infância (DGP/CNPq), vinculado a PUC Minas, 


\section{Revista Espaço do Currículo}

ISSN $1983-1579$

http://periodicos.ufpb.br/ojs2/index.php

denunciam "práticas que reafirmam a invisibilidade social das novas gerações, por vezes reforçada dentro das instituições de educação infantil por meio de um desenho curricular pensado pelos adultos para as crianças e que muito pouco contempla os anseios dos sujeitos de pouca idade".

Para Jose Damião Rocha, professor do Programa de Pós-Graduação em Educação (PPGE) da Universidade Federal do Tocantins (UFT), no manuscrito Currículo "toy story" da educação infantil: por um currículo brincante e brincalhão para bebês e crianças pequenas, ao apresentar investigações sobre o brincar, brinquedos, brincadeiras e materiais na transição do bebê, da casa à creche ou às instituições congêneres defende que tais temas devem ser fundantes na formação do professores e constar nos currículos dos cursos de Pedagogia do país.

O texto Currículo e formação do professor de português na visão de docentes de uma licenciatura em Letras, de autoria de Ewerton Ávila dos Anjos Luna, professor da Universidade Federal Rural de Pernambuco, investigou como docentes universitários veem o currículo da licenciatura em Letras em que atuam e como usam estratégias para moldá-lo. Nos resultados, indica necessidade de maiores diálogos em momentos como o de Reforma Curricular.

O último texto desta primeira parte discorre sobre $A$ formação do docente em história na vertente do multiculturalismo crítico: desafios e perspectivas curriculares. Para Aldieris Braz Amorim Caprini, professor do Instituto Federal do Espírito Santo, problematiza os fundamentos epistemológicos e socioculturais necessários para uma formação multicultural crítica, assim como indica pontos para subsidiar caminhos curriculares da formação em História na referida perspectiva.

A segunda parte, apresenta alguns dos temas que emergem das tramas das tessituras constituídas através do currículo. O texto $O$ currículo no centro da luta: contribuições de Michael Apple para a compreensão da realidade escolar, de Marlice de Oliveira e Nogueira, professora da Universidade Federal de Ouro Preto, retoma "a visão crítica de Michael Apple sobre a escola e o currículo como espaços de luta e contestação" destacando que, em tempos "pós-modernos", tais fundamentos são importantes para uma análise em profundidade da escola que temos hoje.

No manuscrito intitulado Usos e consumos no/do cotidiano escolar: uma conversa sobre práticas, currículos e livros didáticos, de Rafael Marques Gonçalves, professor da Universidade Federal do Acre, discute o escopo de alternativas políticaspráticas possíveis para combater os discursos que atacam de forma exacerbada a legitimidade do espaçotempo escolar e a atuação docente nas escolhas cotidianas.

O texto intitulado Escola Cidadã Integral: proposições curriculares para jovens do Ensino Médio, de autoria de Ana Cláudia da Silva Rodrigues professora vinculada ao Programa de Pós-graduação em Educação da Universidade Federal da Paraíba, discute a constituição de uma agenda de proposições para a implementação e consolidação da Educação Integral no Brasil nas últimas décadas através da implementação de programas, por entes federativos, que ratificam o direito a outros tempos e espaços educativos (MOLL, 2012).

O texto intitulado As perspectivas de integração no currículo da educação profissional integrada à EJA de autoria de Márcia Castilho Sales e do professor Renato Hilário Reis, vinculado a Universidade Federal de Brasília/DF, apresenta as diferentes perspectivas de integração do ensino Médio integrado a EJA, apresentando a integração a partir do itinerário formativo.

No texto A reforma do ensino médio como mecanismo de intensificação do dualismo escolar, Rosimar Serena Siqueira Esquinsani, Valdocir Antonio Esquinsani, pesquisadores do Programa de Pós-Graduação em Educação da Universidade de Passo Fundo, problematiza-se a organização curricular desta etapa da Educação Básica e as possibilidades dessa organização representar - após a Lei nº 13.415/2017 -, a intensificação desse dualismo.

Ainda sobre o mesmo tema no manuscrito sobre A reforma do ensino médio brasileiro como estratégia biopolítica de governo, de autoria de Gicele Maria Cervi, Amarildo Inácio dos Santos, 
pesquisadores vinculados ao Programa de Pós-graduação em Educação da Universidade Regional de Blumenau, infere-se que a reforma do ensino médio brasileiro visa alinhar o currículo do Ensino Médio com a atual ordem mental e social, a fim de produzir o sujeito necessário a essa ordem, o homo oeconomicus neoliberal.

O texto Utopias e regulações de uma base nacional comum curricular: projeções ficcionais para juventudes ideais, de William de Goes Ribeiro, professor da Universidade Federal Fluminense, aborda questões sobre diferença e como esta é posta à margem, no texto da BNCC, pelo instituído no qual o jovem precisa se adequar.

Concluímos com o texto $O$ projeto escola sem partido e a função social da escola: avanços ou retrocessos? Cuja autoras Samira de Moraes Maia Vigano, Maria Hermínia Lage Fernandes Laffin, vinculadas ao Programa de Pós Graduação da Universidade Federal de Santa Catarina, verificaram que o Projeto Escola sem Partido "tem como base o cerceamento do currículo no que tange as discussões de gênero e sexualidade e que essa proibição resulta em formações homofóbicas e misóginas, fortalecendo um currículo segregador das diferenças".

Desejamos uma ótima leitura e que os textos publicados possam enriquecer o debate, gera discussões e contestações contribuindo para a divulgação e avanço dos estudos curriculares no país!

\section{REFERENCIAS}

APPLE, Michael W. Política Cultural e Educação. São Paulo: Cortez, 2000.

AKKARI, Abdeljalil. Internacionalização das políticas educacionais: transformações e desafios. Petrópolis: Vozes, 2011.

BALL, S.J.; BOWE, R. Subject departments and the "implementation" of National Curriculum policy: an overview of the issues. Journal of Curriculum Studies, London, v. 24, n. 2, p. 97-115, 1992.

BALL, Stephen J. Global Education Inc.:new policy networks and the neo-liberal imaginary.London: Routledge; New York: Taylor \& Francis Group, 2012.

BARDIN, Laurence. Análise de conteúdo. São Paulo: Edições 70, 2011.

GOODSON, Ivor F. As políticas de currículo e de escolarização: abordagens históricas. Tradução de Vera Joscelyne. Petropolis, Rj, vozes, 2008.

LOPES, Alice Casimiro; CUNHA, Erika Virgílio Rodrigues da; COSTA, Hugo Heleno Camilo. Da recontextualização à tradução: investigando políticas de currículo. Currículo Sem Fronteiras, v. 13, n.3, p.392-410, set./dez., 2013.

LOPES, Alice Casimiro. Teorias pós-críticas, política e currículo. Educação, Sociedade \& Culturas, nº 39, 2013, 7-23.

MOLL, Jaqueline (Org.). Caminhos da Educação Integral no Brasil: direito a outros tempos e espaços educativos. Porto Alegre: Penso, 2012.504 p.

PINAR, William F. O que é a Teoria do Currículo?. Tradução da Aba Paula Barros e Sandra Pinto. Porto: Porto Editora, 2007.

ROSA, Sanny Silva. Entrevista com Stephen J. Ball - Privatizações da educação e novas subjetividades: contornos e desdobramentos das políticas (pós) neoliberais. Revista Brasileira de Educação v.18, n.53, p.457-466, abr.-jun, 2013. 